\title{
Effect of weight percent of tetrapropoyl ammonium hydroxide solution on chemical and photocatalytic properties of titanium dioxide nanoparticles
}

\author{
KS Al-Namshah, ES Baeissa* and RM Mohamed \\ *Faculty of Science, Chemistry Department, King Abdulaziz University, Jeddah, Saudi Arabia
}

\begin{abstract}
A sol-gel method was used to prepare four samples of Titanium dioxide $\mathrm{TiO}_{2}$ by different weight percent of tetrapropoyl ammonium hydroxide solution(TPAOH). The effect of different weight percent of TPAOH on the properties and efficiency of $\mathrm{TiO}_{2}$ was studied to degradation of methylene blue ( $\mathrm{MB}$ ) dye. The samples were characterized with $\mathrm{X}$-ray diffraction(XRD), ultraviolet and visible spectroscopy (UV-Vis), Photoluminescence (Pl) emission spectra, surface area measurements (BET), and transmission electron microscopy (TEM). Furthermore, the photocatalytic performance of $\mathrm{TiO}_{2}$ was measured in the degradation of methylene blue (MB) dye. The results demonstrate that the best weight percent of TPAOH for the preparation of TiO2 nanoparticles at high properties and efficiency is 2.88 wt $\%$.
\end{abstract}

\section{Introduction}

For the past ten years, the growth in population, development of technological, industrial and agricultural expansions have affected the environment and the health of human beings in society [1]. In the environment have been searching for suitable techniques of eliminating hazardous dye discharges that are released in the water bodies that result in the increase of dangerous environmental harms that have an effect on the health of human beings and the marine medium [2,3]. There have been many advances that have been incorporated to reduce the rate of toxicity caused by these dyes, methylene blue (MB) from the water [4], pinpoint these methods that include adsorption, especially on high plane area chains precipitation of chemicals, biological membranes, and ion-exchange processes and also through sedimentation [5]. These methods were considered to be effective in the removal of these chemical dyes although the processes were considered to be slow and there was the need to incorporate expensive materials in the removal of these dyes in the photocatalysis process. Also, these methods led to the researches being conducted on the of the sol-gel method in the synthesis of $\mathrm{TiO}_{2}$ nanoparticles in the process. Its relevance was also researched in the photocatalytic deprivation of methylene blue through the use of Titanium dioxide [6,7]. The synthesis of $\mathrm{TiO}_{2}$ nanoparticles by the sol-gel method is among the suggested techniques among the many techniques including the use of $\mathrm{Cu}_{2} \mathrm{O}$ that has been used widely in photocatalysis as a typical photoelectrode in the electrochemical cells especially under irradiation by visible light [8]. The splitting of water produced hydrogen fuel, although the fuel was not enough to be used in the process of combustion. This raised many debates in the research of suitable techniques of degradation of dyes such as methylene blue (MB) that were suggested in the removal of these effluent substances from our ecosystem [9]. However, the advantages attached to the use of $\mathrm{TiO}_{2}$ and that which is doped as photo-catalysts triggered the research in this field [10]. Latest studies have paid attention to the use of $\mathrm{TiO}_{2}$ based photocatalysts for the filth of dyes in the aqueous solutions. Nanocrystalline $\mathrm{TiO}_{2}$ is an oxide semiconductor material that had been studied in numerous experiments to develop a photocatalytic water treatment process that is efficient $[11,12]$. The process where $\mathrm{TiO}_{2}$ is used is characterized by high reaction rates and short periods of treatment that arise due to the quick oxidation processes caused by the hydroxyl radicals [13]. The study of these uses motivated the research and development of the several techniques employed in the preparation of catalysts that are used for different tasks in the degradation of methylene blue [14]. There is the need for the increase in the catalytic activity so as to enhance the competence of the whole process especially if the process is to be incorporated in the treatment of water in large scales [15]. The resourcefulness of $\mathrm{TiO}_{2}$ gives it a wide application in different areas of various products such as the manufacturing of pigments, development of electrochemical electrodes, in the production of toothpaste and capacitors [16]. Also, the oxidation process of the photocatalytic process where semiconductors such as $\mathrm{TiO}_{2}, \mathrm{CdS}, \mathrm{Cu}_{2} \mathrm{O}$, and $\mathrm{ZnO}$ has been widely studied in the past has been a point of concern in the degradation process of methylene blue (MB) [17]. This was due to the attention brought about by the hazardous organic substances released into the environment by the textile, technological and agricultural industries strive to produce products that are extensively needed across the globe $[18,19]$. This paper aims at synthesizing Titanium dioxide $\left(\mathrm{TiO}_{2}\right)$ nanoparticles via the sol-gel method and evaluating the application of $\mathrm{TiO}_{2}$ to the photocatalytic degradation of the dye direct blue.

\section{Experimental}

\section{Photocatalyst preparation}

All chemicals in this experiment were analytical grade and used

Correspondence to: ES Baeissa, Chemistry Department, Faculty of Science, King Abdulaziz University, Jeddah 21589, Saudi Arabia, Tel: +966-6400000; Fax: +966-2-6952292. E-mail: elhambaeissa@gmail.com

Key words: Sol-gel, $\mathrm{TiO}_{2}$, Tetrapropoyl ammonium hydroxide, $\mathrm{MB}$ dye

Received: July 03, 2016; Accepted: July 27, 2016; Published: July 30, 2016 
Al-Namshah KS (2016) Effect of weight percent of tetrapropoyl ammonium hydroxide solution on chemical and photocatalytic properties of titanium dioxide nanoparticles

as received without further purification. Titanium dioxide $\mathrm{TiO}_{2}$ nanoparticles were prepared via sol-gel method according to the following route: different weight percent of tetrapropoyl ammonium hydroxide solution $(\mathrm{TPAOH})(10 \%)(0.96,1.44,2.88$, and $3.92 \%)$ were added to the mixture of $5.28 \mathrm{ml}$ distilled water, $16.8 \mathrm{ml}$ ethanol (96\%) and $0.05 \mathrm{ml}$ nitric acid with constant stirring at room temperature for $1 \mathrm{hr}$. Then, $5 \mathrm{ml}$ of Titanium(IV) butoxide (TBT) (97\%), was added slowly with constant stirring at room temperature for another $1 \mathrm{hr}$. The produced white precipitate were collected by centrifugation, filtration, washing, and dried in a vacuum oven at $60^{\circ} \mathrm{C}$ for $24 \mathrm{hrs}$, crushed to fine powder followed and heated at $550^{\circ} \mathrm{C}$ for $5 \mathrm{~h}$ in muffle furnace.

\section{Characterization techniques}

$\mathrm{X}$-ray diffraction (XRD) analysis was performed at room temperature with a Bruker axis D8, using $\mathrm{Cu} K \propto$ radiation $(\lambda=1.540$ $\left.A^{\circ}\right)$. The specific surface area was calculated from measurements of $\mathrm{N}_{2}$ adsorption with a Nova 2000 series Chromatech apparatus at 77 $\mathrm{K}$. Prior to measurement, all samples were treated for $2 \mathrm{~h}$ under a vacuum at $200^{\circ} \mathrm{C}$. The band gap of the samples was identified using UV-Vis diffuse reflectance spectra (UV-Vis-DRS) in air at room temperature in the wavelength range of $200-800 \mathrm{~nm}$, with an UV/ Vis/NIR spectrophotometer (V-570, JASCO, Japan). Transmission electron microscopy (TEM) was recorded with a JEOL-JEM-1230 microscope, and the samples were prepared by suspending them in ethanol, thereafter ultrasonication for $30 \mathrm{~min}$. placing a small amount of this solution onto a carbon-coated copper grid and dried the solution before loading the sample in the TEM.

\section{Photocatalytic test}

The photocatalytic activity test was studied by study degradation of methylene blue (MB) under UV light irradiation. The degradation reactions were carried out in a Pyrex glass beaker. The photocatalytic activity experiment was performed by adding $0.1 \mathrm{~g}$ of photocatalyst into the beaker with $300 \mathrm{ml}$ aqueous methylene blue solution ( $50 \mathrm{ppm}$ ). This mixture was placed inside the photocatalytic reactor for 60 minutes and then $\mathrm{O}_{2}$ flow was bubbled through the reactor with constant flow rate to keep the mixture homogeneous. The reaction was initiated irradiation process when the UV-lamp was switched on. The experiment was performed at room temperature and $\mathrm{pH}$ about 7 . The resulting mixture was taken after irradiation and the catalyst separated from solution by centrifugation process. After that, the content of methylene blue in the solution after irradiation was determined by monitor the absorbance of $\mathrm{MB}$ solutions under constant experimental conditions using $\mathrm{UV}-\mathrm{V}$ is spectrophotometer which was recorded on a Shimadzu UV-2450 with $1 \mathrm{~cm}$ (path length) quartz cuvette. The photodegradation efficiency of methylene blue was calculated by applying the following equation:

$$
\% \text { Photo deg radationefficiency }=\frac{\mathcal{C}_{0}-c}{\mathcal{C}_{0}} \times 100
$$

Where $\mathrm{C}_{0}$ is the original content of methylene blue and $\mathrm{C}$ is the residual methylene

blue in solution.

\section{Results and discussion}

\section{Photocatalysts characterization}

Phase analysis: $\mathrm{TiO}_{2}$ nanoparticles which prepared by different weight percents of tetrapropoyl ammonium hydroxide solution (TPAOH) were characterized by X-ray diffraction (XRD) analysis to determine their phase compositions. The X-ray diffraction patterns of
$\mathrm{TiO}_{2}$ nanoparticles prepared by different weight percent of $(\mathrm{TPAOH})$ were shown in Figure 1. The results reveal that $\mathrm{TiO}_{2}$ phase is present for all samples as a pure $\mathrm{TiO}_{2}$ phase. As the weight percents of tetrapropoyl ammonium hydroxide solution was increased, the diffraction peaks of the samples gradually became narrow and sharp. This change indicates that the particle size grew as weight percent of TPAOH increased.

Surface area analysis: The Specific surface area (SBET) of $\mathrm{TiO}_{2}$ nanoparticles which were prepared by different weight percent of tetrapropoyl ammonium hydroxide solution (TPAOH) such as $0.96 \%$, $1.44 \%, 2.88 \%$ and $3.92 \%$ are tabulated in Table 1 . The results reveal that the surface area of the $\mathrm{TiO}_{2}$ obtained at $2.88 \mathrm{wt} \%$ is $138 \mathrm{~m}^{2} / \mathrm{g}$. As the weight percent increases, the surface area is increases from 80 $\mathrm{m}^{2} / \mathrm{g}$ at $0.96 \mathrm{wt} \%$ to $140 \mathrm{~m}^{2} / \mathrm{g}$ at $3.92 \mathrm{wt} \%$. There was no significant change when adding $3.92 \mathrm{wt} \%$ of tetrapropoyl ammonium hydroxide solution. Thus, the $\mathrm{TiO}_{2}$ prepared by $2.88 \mathrm{wt} \%$ of tetrapropoyl ammonium hydroxide solution (TPAOH) is expected to have the highest photocatalytic activity, due to it has highest specific surface area which provide active sites to promote the adsorption capacity leading to higher photocatalytic activity.

\section{Optical characterization}

The study of UV-Vis radiation absorption constitutes an important agent for the evaluation of the changes produced in prepared nanoparticles by different treatments. The band gab of pure $\mathrm{TiO}_{2}$ phase is usually reported $3.2 \mathrm{eV}$. The UV-Vis diffuse reflectance spectra of $\mathrm{TiO}_{2}$ nanoparticles which prepared by different weight percent of tetrapropoyl ammonium hydroxide solution are show in Figure 2. The results reveal that the absorbance edges of the $\mathrm{TiO}_{2}$ samples regularly varied. As the weight percents of tetrapropoyl ammonium hydroxide solution (TPAOH) increased, the absorbance edges of the samples moved gradually to higher wavelength (shift on band gap to lower value), In UV-Vis/DR spectrum of samples the threshold edge of absorption band is observed in the range shorter than $400 \mathrm{~nm}$ in the area of the spectrum ultraviolet. The UV-Vis reflectance spectra, were used to calculate The band gap values of $\mathrm{TiO}_{2}$ samples by direct extrapolation the absorption edge by linear fit method with the onset corresponding wavelengths, using the following equation:



Figure 1. XRD patterns of as-synthesized $\mathrm{TiO}_{2}$ nanoparticles prepared at different weight percent of TPAOH. 
Al-Namshah KS (2016) Effect of weight percent of tetrapropoyl ammonium hydroxide solution on chemical and photocatalytic properties of titanium dioxide nanoparticles

Table 1. BET surface area of $\mathrm{TiO}_{2}$ nanoparticles prepared at different weight percent of TPAOH.

\begin{tabular}{|c|c|}
\hline Samples & Surface area $\left(\mathbf{m}^{2} / \mathbf{g}\right)$ \\
\hline $0.96 \mathrm{wt} \% \mathrm{TPAOH}-\mathrm{TiO}_{2}$ & 80 \\
\hline $1.44 \mathrm{wt} \% \mathrm{TPAOH}-\mathrm{TiO}_{2}$ & 100 \\
\hline $2.88 \mathrm{wt} \% \mathrm{TPAOH}-\mathrm{TiO}_{2}$ & 138 \\
\hline $3.92 \mathrm{wt} \% \mathrm{TPAOH}-\mathrm{TiO}_{2}$ & 140 \\
\hline
\end{tabular}



Figure 2. UV-Vis absorption spectra of $\mathrm{TiO}_{2}$ nanoparticles prepared at different weight percent of TPAOH.

Table 2. Band gap of $\mathrm{TiO}_{2}$ nanoparticles prepared by different weight percent of TPAOH.

\begin{tabular}{|c|c|}
\hline Samples & Band gap, eV \\
\hline 0.96 wt $\%$ TPAOH- $\mathrm{TiO}_{2}$ & 3.54 \\
\hline $1.44 \mathrm{wt} \% \mathrm{TPAOH}-\mathrm{TiO}_{2}$ & 3.38 \\
\hline $2.88 \mathrm{wt} \% \mathrm{TPAOH}-\mathrm{TiO}_{2}$ & 3.20 \\
\hline $3.92 \mathrm{wt} \% \mathrm{TPAOH}-\mathrm{TiO}_{2}$ & 3.12 \\
\hline
\end{tabular}

\section{$E(e v)=1239.8 / \lambda(n m)$}

The band gap value calculated for the prepared samples are demonstrated in Table 2. The results show that the band gap for $\mathrm{TiO}_{2}$ nanoparticles prepared by $0.96 \mathrm{wt} \%, 1.4 \mathrm{wt}, 2.88 \mathrm{wt} \%$ and $3.92 \mathrm{wt} \%$ of tetrapropoyl ammonium hydroxide (TPAOH) are 3.54, 3.38, 3.20 and $3.12 \mathrm{eV}$, respectively, It is clear that the band gap decreased with increase wt\% of tetrapropoyl ammonium hydroxide(TPAOH). So, the weight percent plays an important role in determining the band gap of the samples $\mathrm{TiO}_{2}$.

Pl emission spectra were measured for samples excited at 265 $\mathrm{nm}$ at room temperature. Pl spectra were used to study the transfer of photogenerated electrons and holes and understand the separation and recombination of photogenerated charge carriers in the samples. $\mathrm{Pl}$ emission spectra is shown in Figure 3. The results reveal that $\mathrm{Pl}$ intensity decreased by increasing the weight percent of TPAOH. Also, we noticed that the position of emission spectra of $\mathrm{TiO}_{2}$ was shifted to longer wavelength as weight percent of TPAOH was increased, which are agree with UV-Vis results. The band gap estimated from PL emission spectra are very close to that estimated from UV-Vis spectra, indicating a decrease in the band gap energy and an increase in the amount of photogenerated electrons and holes available to contribute in photocatalytic reactions.

\section{TEM analysis}

Figure 4 shows TEM images of $\mathrm{TiO}_{2}$ nanoparticles, prepared by different weight percent of TPAOH. The results demonstrated that the shape of $\mathrm{TiO}_{2}$ samples is a spherical shape. On increasing the weight percent of tetrapropoyl ammonium hydroxide from $0.96 \%$ to $1.44 \%$ increase the overall particle size of the produced nanoparticles. After increase in weight percent to $2.88 \%$, there was decrease in particle size. Again, When weight percent is increase to $3.92 \%$ there was increase in particle size.

\section{Photocatalytic oxidation of MB-dye using $\mathrm{Tio}_{2}$ nanoparticles under UV irradiation light}

The photocatalytic activity of $\mathrm{TiO}_{2}$ nanoparticles prepared by different weight percent of tetrapropoyl ammonium were tested using solution of methylene blue (MB) under UV light irradiation after 60 minutes are shown in Figure 5. The results reveal that as increase



Figure 3. $\mathrm{Pl}$ spectra of $\mathrm{TiO}_{2}$ nanoparticles prepared at different weight percent of TPAOH


Figure 4. TEM images of $\mathrm{TiO}_{2}$ prepared at different weight percent of TPAOH, where, weight percent of TPAOH is $0.96(\mathrm{~A}), 1.44(\mathrm{~B}), 2.88(\mathrm{C})$ and $3.92(\mathrm{D})$. 
Al-Namshah KS (2016) Effect of weight percent of tetrapropoyl ammonium hydroxide solution on chemical and photocatalytic properties of titanium dioxide nanoparticles

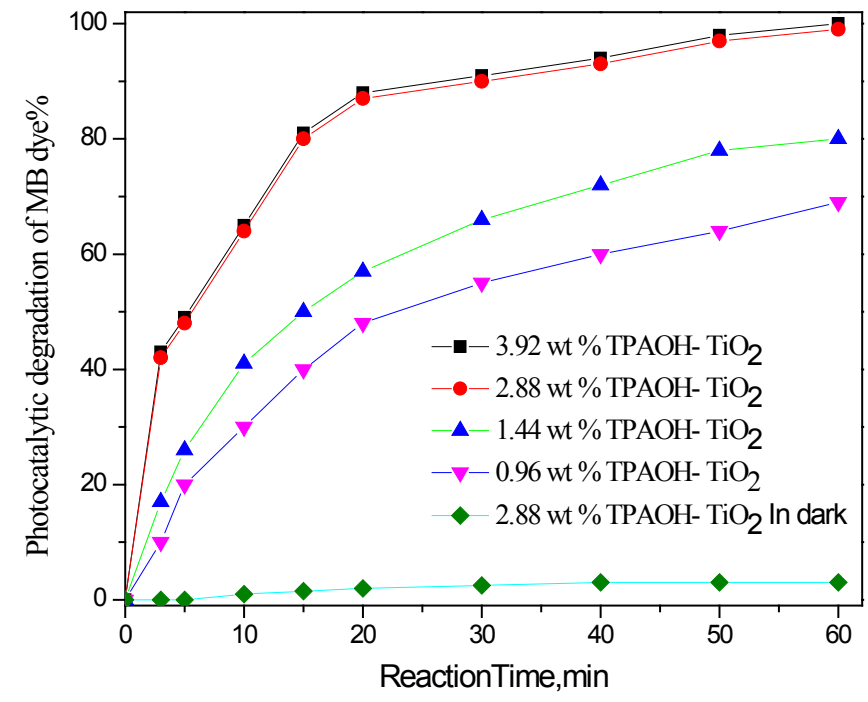

Figure 5. Photocatalytic degradation of $\mathrm{TiO}_{2}$ nanoparticles prepared by different weight percent of TPAOH.

wt $\%$ of TPAOH from 0.96 to $3.92 \%$, increase photocatalytic activity from 69 to $100 \%$, respectively. However, increase $\mathrm{wt} \%$ of $\mathrm{TPAOH}$ above $2.88 \%$, i.e., $3.92 \%$, has no significant effect on photocatalytic activity. Therefore, the optimum wt $\%$ of TPAOH is $2.88 \mathrm{wt} \%$ at which photocatalytic activity is $99 \%$.

\section{Conclusions}

A sol-gel method was used to prepare four samples of titanium dioxide $\mathrm{TiO}_{2}$ by different concentrations of tetrapropoyl ammonium hydroxide solution. In UV-Vis/DR spectrum of samples the threshold edge of absorption band is observed in the range shorter than $400 \mathrm{~nm}$ in the area of the spectrum ultraviolet. The highest wavelength of the $\mathrm{TiO}_{2}$ prepared by $2.88 \mathrm{wt} \%$ of TPAOH is $386.85 \mathrm{~nm}$ (shift on band gap to lower value), and It has lowest PL intensity, which means it has low rate of recombination of photogenerated electron- hole pairs. Therefore, the weight percent of TPAOH plays an important role in determining properties and efficiency samples of Titanium dioxide. Measurements of the photocatalytic degradation of methylene blue (MB) dye reveal that $\mathrm{TiO}_{2}$ prepared by $2.88 \mathrm{wt} \%$ of $\mathrm{TPAOH}$ exhibited the highest photocatalytic activity and active photocatalytic properties for water purification and may find potential applications in related fields.

\section{References}

1. Herna'ndez-Rami'rez A, Medina-Rami'rez I (2014) Photocatalytic semiconductors: Synthesis, characterization, and environmental applications. Springer.
2. Alca^ntara ACS, Kalia S (2015) Organic-inorganic hybrid nanomaterials. Berlin: Springer.

3. Hussein AK (2015)Applications of nanotechnology in renewable energies-A comprehensive overview and understanding. Renewable and Sustainable Energy Reviews 42: 460-476

4. Morales-Torres S, Pastrana-Martínez LM (2014) Nanostructured carbon-TiO2 photocatalysts for water purification: an overview.

5. Zhao Z, Sun ZC, Zhao HF, Zheng M, Du P, et al. (2012) Phase control of hierarchically structured mesoporousanatase $\mathrm{TiO} 2$ microspheres covered with facets. J Mater Chem 22: $21965-21971$

6. Ding X, Zhou S, Jiang L, Yang H ( 2011) Preparation, photocatalyticactivity and mechanism of nano-Titania/Nafion hybrid membrane. J Sol-Gel Sci Technol 58: $345-$ 354.

7. Chen X, Mao SS (2007) Titanium dioxide nanomaterials: synthesis, properties, modifications, and applications. Chem Rev 107: 2891-2959. [Crossref]

8. Lu X, Song C, Jia S, Tong Z, Tang X, Teng Y (2015) Low-temperature selective catalytic reduction of NOxwith $\mathrm{NH} 3$ over cerium and manganese oxides supported on $\mathrm{TiO}_{2}$-graphene. Chem Eng J 260: 776-784.

9. Liu Y, Yang Q, Wei J, Xiong R, Pan C. X, Shi J (2011)Synthesis and photocatalytic activity of hydroxyapatite modifiednitrogen-doped TiO2. Mater Chem Phys 129: 654659

10. Lonnen J, Kilvington S, Kehoe SC, Al-Touati F, McGuigan KG (2005) Solar and photocatalytic disinfection of protozoan, fungal and bacterial microbes in drinking water. Water Res 39: 877-883. [Crossref]

11. Li D, Haneda H (2003) Synthesis of nitrogen-containing ZnO powdersby spray pyrolysis and their visible-light photocatalysis in gasphaseacetaldehyde decomposition. J Photochem Photobiol A 155: 171-178.

12. Kamat PV, Meisel D (2002) Nanoparticles in advanced oxidation processes. Curr Opin Colloid Interface Sci 7: 282-7.

13. Daghrir R, Drogui P, Robert D (2012) Photoelectrocatalytic technologies for environmental applications. A Journal of Photochemistry and Photobiology. Chemistry 238: 41-52.

14. Han H, Ba R (2009) Buoyant photocatalyst with greatly enhanced visible-light activityprepared through a low temperature hydrothermalmethod. Ind EngChem Res 48: $2891-2898$

15. Herna'ndez-Rami'rez A, Medina-Rami'rez I (2014) Photocatalytic semiconductors: Synthesis, characterization, and environmental applications. Springer.

16. Diallo MST, Fromer NA, Jhon MS (2014) Nanotechnology for sustainable development.

17. Govindaraj R, Pandian MS, Ramasamy P, Mukhopadhyay S (2015) Sol-gel synthesized mesoporous anatase titanium dioxide nanoparticles for dye sensitized solar cell (DSSC) applications. Bulletin of Materials Science 38: 291-296.

18. Dawson G, Chen W, Zhang T, et al.( 2010) A study on the effect of startingmaterial phase on the production of trititanate nanotubes. Solid State Sci 12: 2170-2176

19. Aparicio M, Jitianu A, Klein LC (2012)Sol-Gel processing for conventional and alternative energy. New York: Springer.

Copyright: (C2016 Al-Namshah KS. This is an open-access article distributed under the terms of the Creative Commons Attribution License, which permits unrestricted use, distribution, and reproduction in any medium, provided the original author and source are credited. 